\title{
Method for One Step DDT Extraction and Cleanup in Tobacco for Monitoring Purposes*
}

\author{
by L. Toet and Mary J. Toet \\ Tobacco Research Board of Rhodesia, Salisbury, Rhodesia
}

\section{INTRODUCTION}

Many methods have been published for routine determination of DDT residues in tobacco for monitoring purposes. Most of them make use of either column chromatography or partitioning between suitable solvents, followed by column cleanup to remove substances likely to interfere with the gas liquid chromatographic (GLC) determination, or cause contamination of electron capture detector (ECD).

Most of these methods are lengthy, cumbersome and require a great deal of attention to detail; also they use large amounts of solvents and make it difficult for one operator to do extractions, cleanup and the GLC work simultaneously.

A one step extraction and cleanup has been developed and the results compared with those obtained by column chromatography. Samples were also analysed in two other laboratories by different methods.

\section{METHODS}

\section{Extraction and Purification}

1. The method used previously (old method) consisted of a Soxhlet extraction (Figure 1 ) of $10 \mathrm{~g}$ tobacco in a sintered glass thimble for $8 \mathrm{~h}$. or more, followed by concentration in a rotary evaporator to $2-3 \mathrm{ml}$ and finally column chromatography in specially designed columns (Figure 2) packed with silica gel (Ramsey and Patterson). The column was eluted in two stages; first with $120 \mathrm{ml}$ petroleum ether (PE) to remove DDT and related compounds, then with $100 \mathrm{ml} \mathrm{5 \%}$ ether in PE to separate the more polar compounds such as dieldrin. This is necessary because $p, p^{\prime}-D D E$ and $o, p^{\prime}-T D E$ are difficult to distinguish from dieldrin by GLC analysis. The volume of the solvent required to remove each pesticide from the silica gel column was determined by adding known amounts of the compounds to pesticide-free tobacco extract and measuring the content of successive $10 \mathrm{ml}$ eluate fractions until none was present.

It is important to keep the activity of the silica gel

* Received for publication: 22nd March, 1973. TRB Research Paper No. 138. constant. This was done in the following way: $50 \mathrm{~kg}$ silica gel were thoroughly mixed to ensure an even distribution of particle size. Smaller airtight containers were filled and used when needed. Only one or two of the smaller samples need to be tested for elution pattern. We found that using this system, the elution pattern remains the same but the contents of each small container should always be remixed properly to ensure uniformity of particle size before withdrawing $7.5 \mathrm{~g}$ aliquots to make the columns.

Two typical elution patterns, one of the elution of pesticides only (Figure 3) and one of the same pesticides added to a pesticide-free tobacco extract (Figure 4) show that tobacco extract influences the elution pattern probably by deactivating the top layer of silica gel and hence allowing the pesticides to elute faster.

2. In the new method, DDT and related compounds were extracted as follows: $5 \mathrm{~g}$ tobacco, $10 \mathrm{~g}$ silica gel and $10 \mathrm{~g}$ sodium sulphate were mixed thoroughly and transferred to a Whatman paper Soxhlet thimble and covered with a previously extracted and dried cottonwool plug. The sample was extracted in PE in a Soxhlet apparatus for $8 \mathrm{~h}$. The flask was removed when the Soxhlet was nearly full (just before siphoning over) and contained about $80 \mathrm{ml}$ of extract. This was cooled to room temperature, made up to $100 \mathrm{ml}$ and was then used for GLC analysis without any further cleanup. Where dieldrin and other more polar pesticides have to be determined the sample can be re-extracted in $5 \%$ ether in $\mathrm{PE}$, or in $10 \%$ acetone to remove compounds such as endosulphan sulphate. ( $\alpha$ - and $\beta$ endosulphan are removed in the first PE extraction.)

\section{APPARATUS AND TECHNIQUES FOR GLC}

This applies to both methods of extraction. All work was done using a dual column, dual ECD Pye Model R chromatograph with two Philips recorders.

\section{Columns and Packings}

For monitoring, a $5 \mu \mathrm{l}$ aliquot is injected into a $0.5 \mathrm{~m}$ column packed with 1.5 to $2.5 \mathrm{~g}$ of $11 \% \mathrm{OV}-17$ and 
Figure 1. Photographs of Soxhlet extractors.
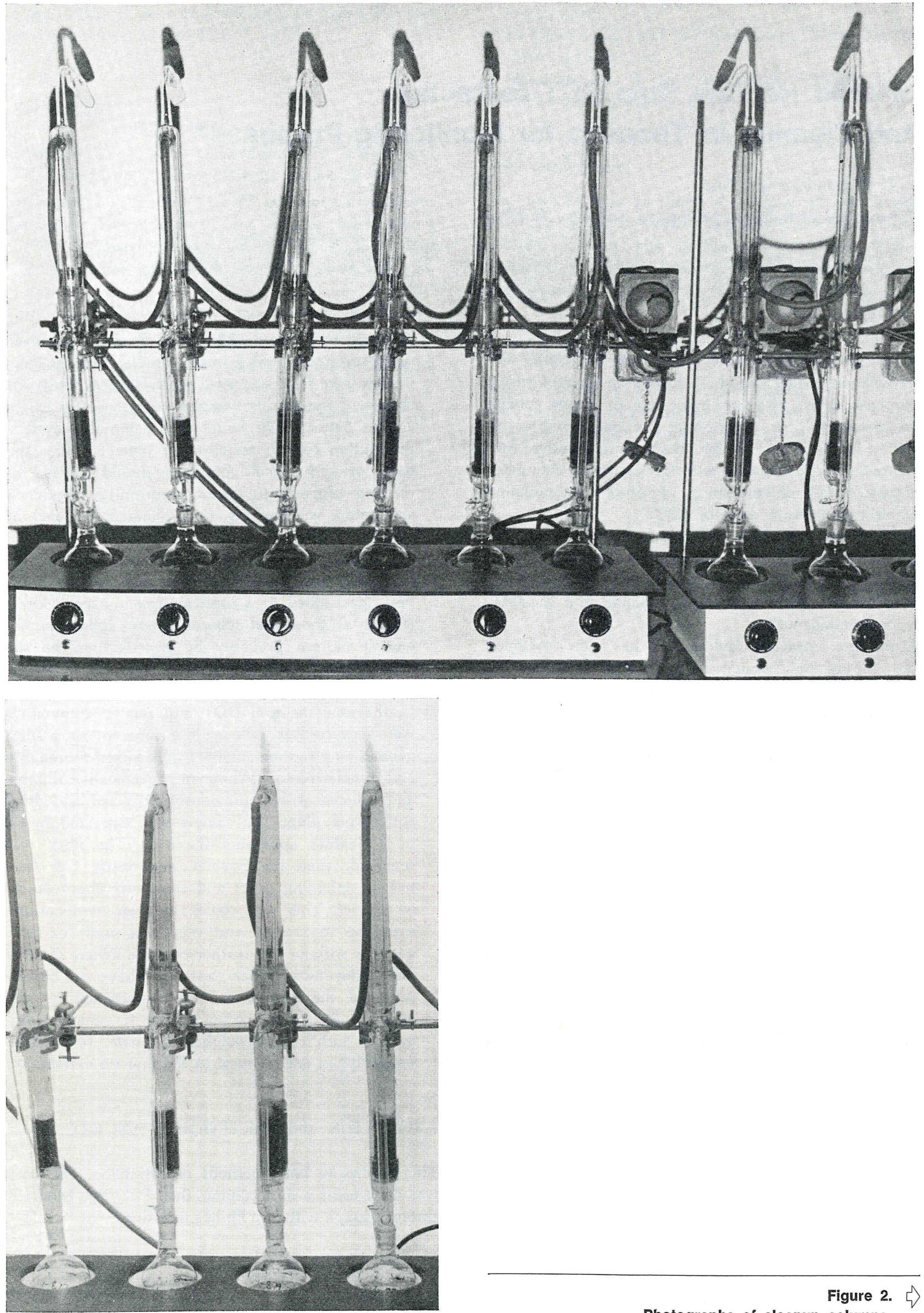

Figure 2. $\downarrow$ 


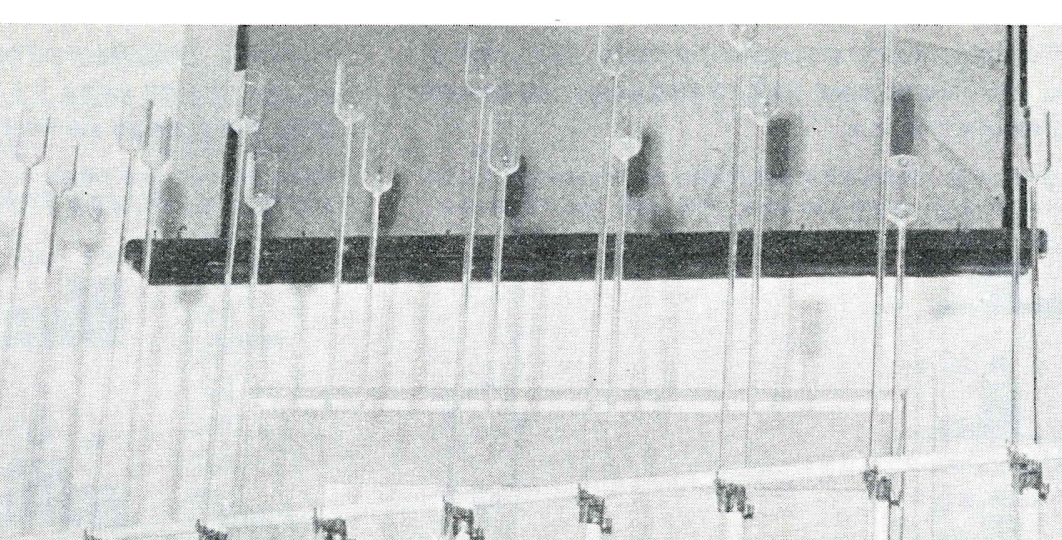

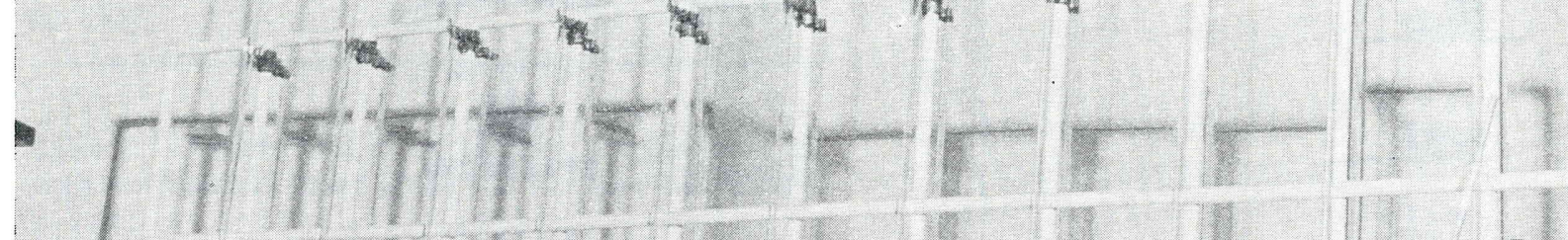

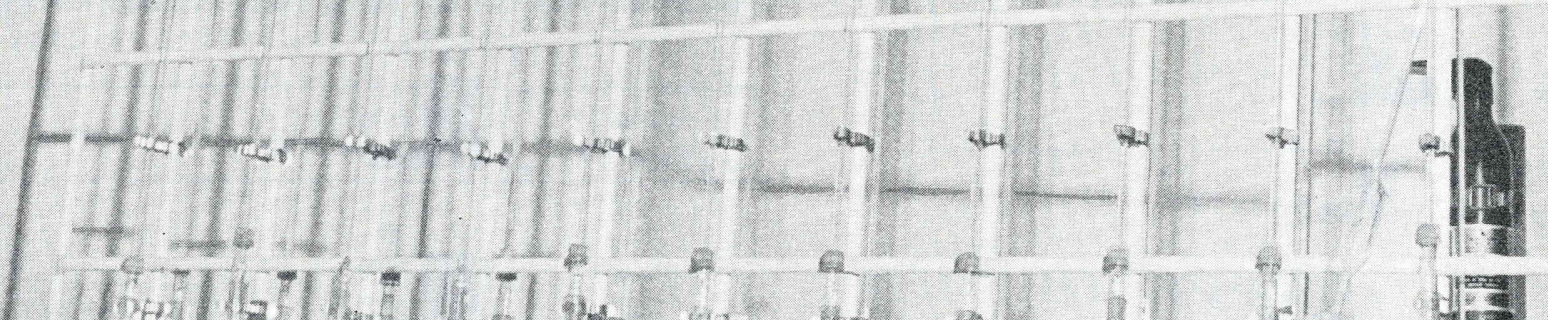

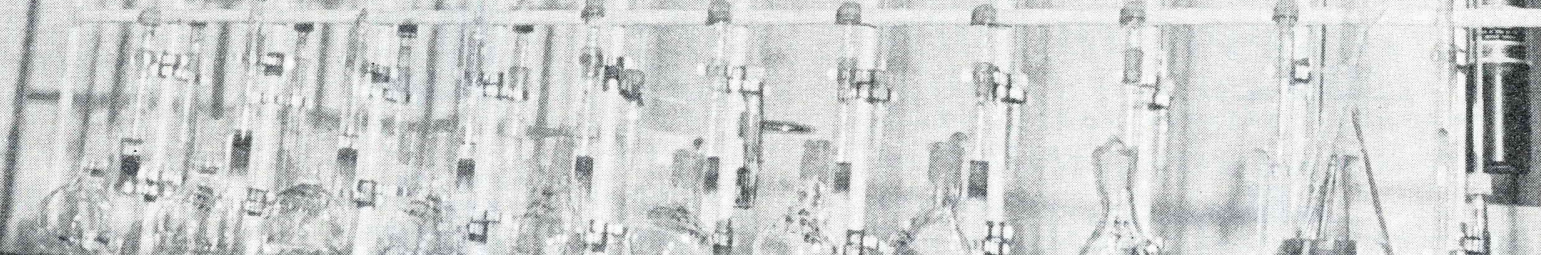

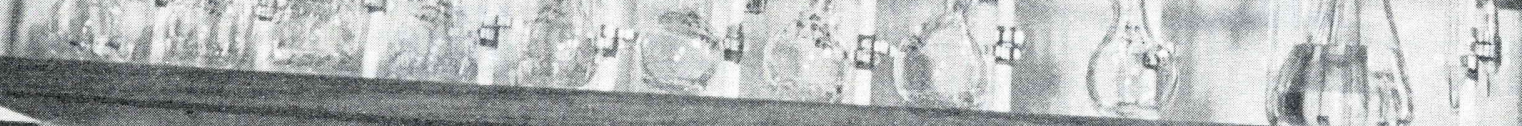

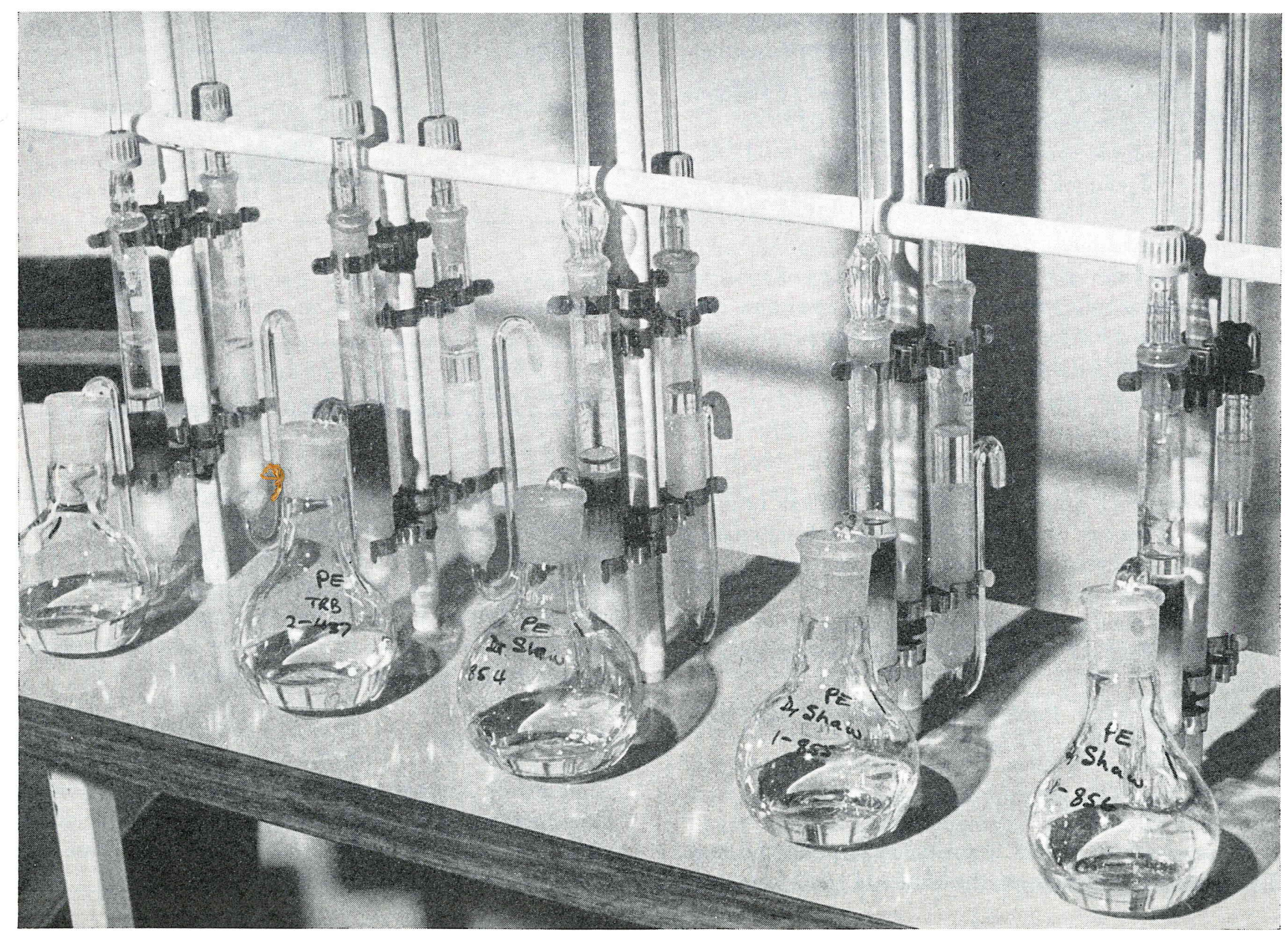


Figure 3. Elution pattern of pesticides only using $7.5 \mathrm{~g}$ silica gel and petroleum ether (PE). Percentage recovered in each $10 \mathrm{ml}$ eluate fraction.

Note: Dieldrin and other more polar pesticides are recovered in the first $40 \mathrm{ml}$ of $5 \%$ ether in petroleum ether (PE) after the PE elution.

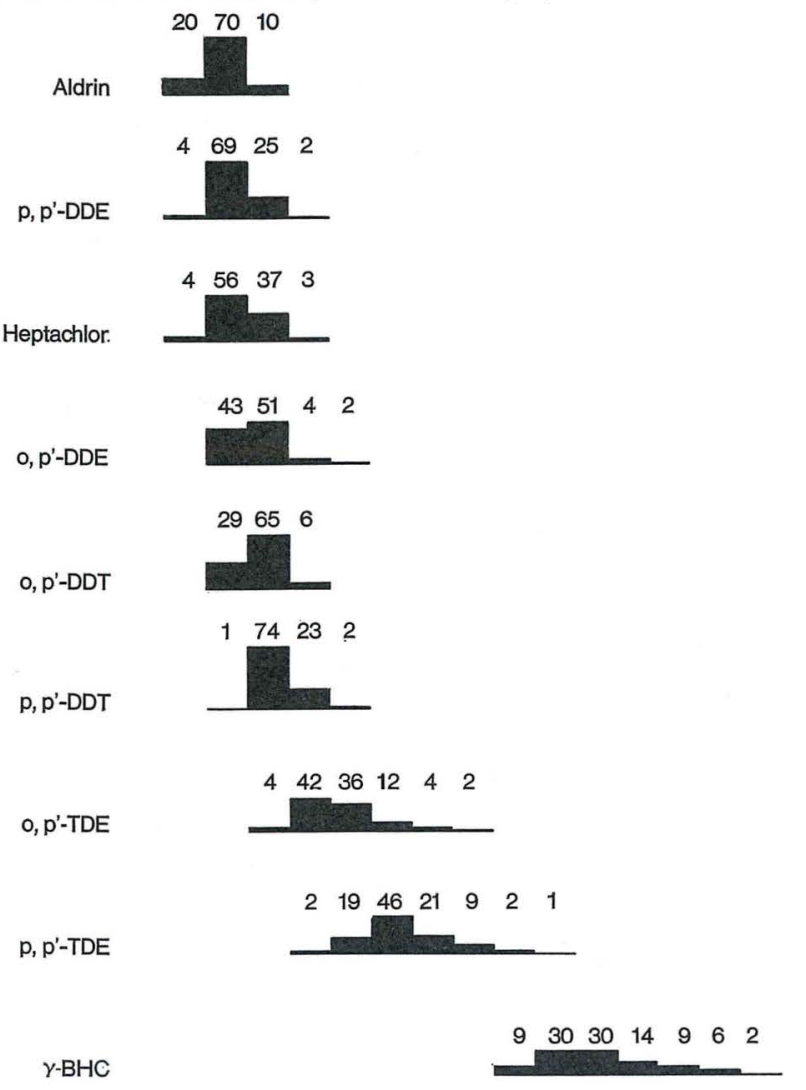

$\begin{array}{lllllllllllllllll}1 & 2 & 3 & 4 & 5 & 6 & 7 & 8 & 9 & 10 & 11 & 12 & 13 & 14 & 15 & 16 & 17\end{array}$ Fraction number ( $10 \mathrm{ml}$ eluate per fraction)

QF-1, I:I (Applied Science Laboratories Inc., Catalogue Number 12970) mixed phase on gas chrom $Q$.

When any sample shows more than $0.5 \mu \mathrm{g} / \mathrm{g}$ total DDT another $5 \mu \mathrm{l}$ aliquot is put through a $1.0 \mathrm{~m}$ column, packed with 2.5 to $3.5 \mathrm{~g}$ of OV-I7 and QF-1, situated in the same machine.

The short column is thus used for screening, flow rates of argon being adjusted so as to give a retention time of $4-5$ minutes for $\mathrm{p}, \mathrm{p}^{\prime}-\mathrm{DDT}$, whereas the long column is made to run so that $\mathrm{p}, \mathrm{p}^{\prime}-\mathrm{DDT}$ comes out at about 10-12 minutes.

\section{Chemicals Used}

a) PE analytical grade, $30^{\circ}-50^{\circ} \mathrm{C}$, distilled once or twice if necessary over $\mathrm{NaOH}$ using refractionating columns. Distillates are tested daily to confirm that they give an acceptable base line.

Note in the new method no concentration of PE takes place. The distilled PE can be tested without concentration.

b) Silica gel after Ramsay and Patterson too mesh Fluka Catalogue Number 60780.

\section{Notes on the Conditioning of Columns}

It is necessary to obtain linearity of response by conditioning the columns at the start of each week, or
Figure 4. Elution pattern of pesticides added to a tobacco extract using $7.5 \mathrm{~g}$ silica gel and petroleum ether (PE). Percentage recovered in each $\mathbf{1 0} \mathrm{ml}$ eluate fraction.

Note: Dieldrin and other more polar pesticides are recovered in the first $30 \mathrm{ml}$ of $5 \%$ ether in petroleum ether (PE) after the PE elution.

Aldrin

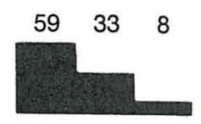

p, p'-DDE

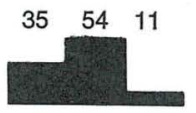

Heptachlor

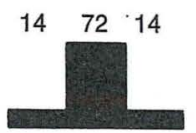

o, p'-DDE

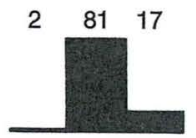

o, p'-DDT

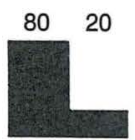

p, p'-DDT

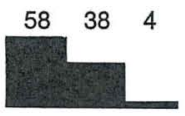

o, p'-TDE

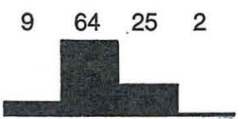

p, p'-TDE

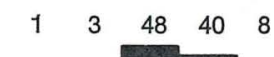

$\gamma-\mathrm{BHC}$

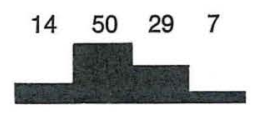

\begin{tabular}{llllllllllll}
1 & 2 & 3 & 4 & 5 & 6 & 7 & 8 & 9 & 10 & 11 & 12 \\
\multicolumn{1}{c}{ Fraction number $(10$} & $\mathrm{ml}$ eluate per fraction $)$
\end{tabular}

after a column has been on standby for longer than 24 hours. A column that had been left on standby for over $24 \mathrm{~h}$. absorbed small amounts of DDT. This affected the results obtained with DDT samples that gave a deflection of $70-90 \%$. To counteract this, DDT was injected regularly, at double the amount expected in the samples, to recondition the column.

\section{Quality Control}

Samples of known pesticide content are processed daily together with blanks. About ten samples of $20 \mathrm{~kg}$ each have been collected and aliquots of these are added to daily samples in random order. 
Table 1. Pesticides recovered by new method.

\begin{tabular}{l|c|c}
\hline \multicolumn{1}{c|}{ Pesticide } & $\mu g / g$ Added & $\%$ Recovery \\
\hline & & \\
\hline -BHC & 0.5 & 100 \\
Heptachlor & 0.4 & 100 \\
Aldrin & 0.4 & 100 \\
o,p'-DDE & 1.0 & 97 \\
p,p'-DDE & 1.0 & 94 \\
o,p'-TDE & 2.0 & 101 \\
o,p'-DDT & 2.0 & 103 \\
p,p'-TDE & 2.0 & 101 \\
p,p'-DDT & 2.0 & 98 \\
\hline
\end{tabular}

Table 2. Results from three tobacco samples done by Tobacco Research Board (TRB) and two other laboratories in 1972.

\begin{tabular}{c|c|c}
\hline Sample & $\begin{array}{c}\text { Total } \\
\text { DDT } \mu \mathrm{g} / \mathrm{g} \mathrm{D} \text {. M. }\end{array}$ & $\begin{array}{c}\text { Dieldrin } \\
\mu \mathrm{g} / \mathrm{g} \mathrm{D} \text {. M. }\end{array}$ \\
\hline
\end{tabular}

QC O

$\begin{array}{lll}\text { TRB } & 0.20 & 0.01 \\ \text { Company 1 } & 0.18 & 0.01 \\ \text { Company 2 } & 0.23 & 0.01 \\ \text { QC X } & & \\ \text { TRB } & 12.0 & 0.01 \\ \text { Company 1 } & 11.07 & 0.00 \\ \text { Company 2 } & 11.3 & 0.01 \\ \text { QC M } & & \\ \text { TRB } & 0.37 & 0.02 \\ \text { Company 1 } & 0.37 & 0.02 \\ \text { Company 2 } & 0.50 & 0.02\end{array}$

N.B. These samples were also done at the University of Malawi and although the results are not yet at hand the provisional results obtained, from private communication, are of the same order.

Table 3. Results on two Kobacco samples, each subsampled five times, done by the old and new method.

\begin{tabular}{|c|c|c|c|}
\hline \multirow{2}{*}{ Sample } & \multirow{2}{*}{ Subsample } & \multicolumn{2}{|c|}{ Total DDT $\mu \mathrm{g} / \mathrm{g}$} \\
\hline & & Old method & New method \\
\hline \multirow[t]{7}{*}{1} & 1 & 10.46 & 10.85 \\
\hline & 2 & 11.16 & 10.46 \\
\hline & 3 & 10.59 & 10.40 \\
\hline & 4 & 9.95 & 10.87 \\
\hline & 5 & 9.51 & 10.70 \\
\hline & Mean & $\overline{10.33} \pm 0.630$ & $10.66 \pm 0.218$ \\
\hline & C.V. $\%$ & 6.1 & 2.0 \\
\hline \multirow[t]{7}{*}{2} & 1 & 0.18 & 0.24 \\
\hline & 2 & 0.18 & 0.22 \\
\hline & 3 & 0.17 & 0.26 \\
\hline & 4 & 0.18 & 0.26 \\
\hline & 5 & 0.18 & 0.24 \\
\hline & Mean & $\overline{0.18} \pm 0,00447$ & $\overline{0.24} \pm 0.0167$ \\
\hline & c.v. $\%$ & 2.5 & 6.9 \\
\hline
\end{tabular}

Figure 5. Scatter diagram of 50 tobacco samples analysed by the old and new method.

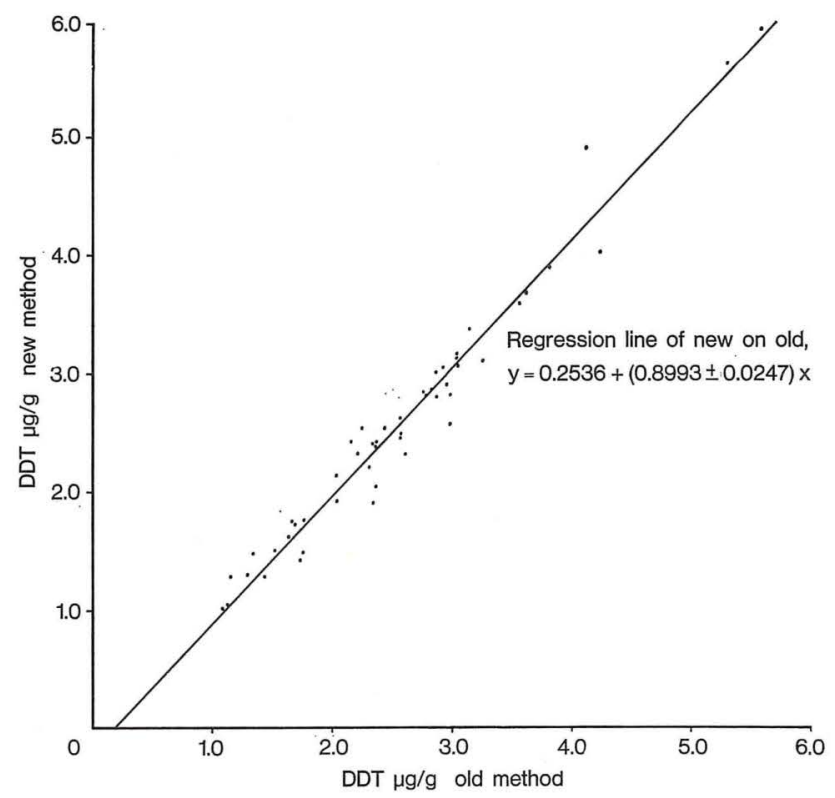

\section{RESULTS AND CONCLUSIONS}

Table $I$ gives the recoveries of various pesticides added in PE solution to tobacco prior to extraction by the new method.

Two international tobacco companies also analysed three tobacco samples containing DDT ranging from $0.2-12.0 \mu \mathrm{g} / \mathrm{g}$. There was very close agreement in the results obtained for DDT and dieldrin contents (Table 2), although three different extraction and cleanup methods were used. We used the new method, one company a combined column extraction and elution on Florisil (Fluka) with PE and the other acetonitrile extraction, column chromatography with Florisil and elution with PE. The new method was as accurate as, quicker and more economical than the other methods.

The old and the new methods were also tested for reproducibility with five aliquots of two tobacco samples containing DDT at approximately 0.2 and II $\mu \mathrm{g} / \mathrm{g}$ (Table 3). The two methods showed good reproducibility; the simplified method had coefficients of variability of 2.0 and 6.9 percent. DDT residue data from fifty tobacco samples extracted by the two methods were very closely correlated $(r=0.98)$ and there was a good fit to the regression line (Figure 5).

\section{SUMMARY}

A simplified extraction and purification method is described for preparing tobacco samples for monitoring organochloride pesticides by GLC. For DDT, only one $8 \mathrm{~h}$. Soxhlet extraction in a paper thimble is necessary. Further extractions can be made for other pesticides such as dieldrin and endosulphan sulphate. No additional column chromatography purification is required before GLC analysis.

The method gives at least as accurate and reproducible 
results as the other methods used for comparison, as well as having the following advantages:

1. Less chemicals are used and the cost per sample is reduced to one fifth of the cost of the old method.

2. The time required for each sample is greatly reduced including ancillary operations such as preparing and cleaning glassware. Thirty or more samples can be done per day including calculations.

3. Because fewer stages are involved in the new method less pesticide is lost from the samples during extraction and reproducibility and accuracy are improved.

\section{ZUSAMMENFASSUNG}

Es wird eine vereinfachte Extraktions- und Reinigungsmethode zur gaschromatographischen Bestimmung von Organochlor-Pestiziden beschrieben. Die Untersuchung der Tabakproben auf DDT erfordert nur eine achtstündige Soxhlet-Extraktion. Für den Nachweis anderer Pestizide wie Dieldrin und Endosulfansulfat können weitere Extraktionen vorgenommen werden. Eine zusätzliche säulenchromatographische Reinigung vor der gaschromatographischen Analyse ist nicht erforderlich.

Das Verfahren liefert Ergebnisse, die wenigstens ebenso genau und reproduzierbar sind wie die anderer Methoden, die zum Vergleich herangezogen wurden. Es hat außerdem die folgenden Vorteile:

I. Es werden weniger Chemikalien verwendet, und die Kosten je Probe betragen nur $1 / 5$ der der alten Methode.

2. Die Analysenzeit je Probe ist einschließlich Vorbereitungs- und Reinigungsschritten stark reduziert. Dreißig und mehr Proben können mit Auswertung je Tag untersucht werden.

3. Durch die vergleichsweise kleinere Zahl von einzelnen Verfahrensschritten gehen in den Proben während der Extraktion weniger Pestizide verloren, und Reproduzierbarkeit wie Genauigkeit sind verbessert.

\section{RESUME}

On décrit une méthode simplifiée d'extraction et de purification, afin de préparer des échantillons de tabac pour contrôler la teneur en pesticides organochlorés par GLC. Pour le DDT, il suffit d'une extraction de $8 \mathrm{~h}$. au Soxhlet dans une timbale de papier. On peut procéder à d'autres extractions pour d'autres pesticides comme le dieldrin et le sulfate d'endosulfane. Il ne faut pas d'autre purification sur colonne chromatographique avant le GLC.

Cette méthode donne des résultats au moins aussi précis et reproductibles que les autres méthodes auxquelles elle a été comparée et possède en plus les avantages suivants:

I. On utilise moins de produits chimiques, et le coût par échantillon est réduit à un cinquième par rapport à l'ancienne méthode.

2. Le temps nécessaire pour chaque échantillon (y compris les opérations annexes comme la préparation et le nettoyage de verrerie) est fort réduit. On peut traiter plus de trente échantillons par jour, y compris les calculs.

3. Puisque cette méthode comporte moins d'étapes que l'ancienne, il y a moins de perte de pesticide pendant l'extraction, et la précision et la reproductibilité sont améliorées.

\section{Acknowledgements}

Mrs. I. Gill for statistical analysis,

Miss L. E. Williams and Miss M. H. C. Ottens

for technical assistance,

Mr. A. Edmondson for assistance with diagrams.

The authors' address:

Tobacco Research Board of Rhodesia, P. O. Box 19o9, Salisbury, Rhodesia. 